\title{
NOTAS SOBRE A VERDADE, O BELO, O BEM E A LINGUAGEM NO JOVEM BENJAMIN
}

Williard Scorpion P. Fragoso ${ }^{1}$ williard.pessoa@hotmail.com

\section{RESUMO:}

O presente artigo desenvolve algumas reflexões sobre a relação entre o conhecimento, o belo e a linguagem no pensamento do jovem Walter Benjamin. Para fazê-lo recorremos a algumas questões contidas em vários textos do autor, tais como: o caráter tautológico do conhecimento científico moderno, a relação possível entre ciência e arte; o caráter extático e indefinível da arte e da verdade, a relação fundamental entre a verdade, o bom e o belo. Para desdobrar a relação entre conceitos, na introdução da obra A Origem do Drama Barroco Alemão de 1926, Benjamin retoma e reinterpreta algumas questões contidas no Banquete de Platão. Também será levado em conta o texto Questões Introdutórias de Crítica do Conhecimento, bem como outros três textos de Benjamin não publicados em vida, quais sejam: A Teoria da Crítica, Categorias de Estética e, por fim, Sobre a Aparência; todos escritos entre os anos 19 e 20 do século $\mathrm{XX}$.

Palavras-Chave: Verdade, Belo, Bem e Linguagem.

\begin{abstract}
:
This paper develops some reflections on the relationship between knowledge, beauty and language in the thinking of the young Walter Benjamin. To do this we turn to some questions contained in various texts of the author, such as the tautological character of modern scientific knowledge, the possible relationship between science and art, the ecstatic and indefinable nature of art and truth, the fundamental relationship between Truth, Good and Beauty. To unfold the relationship between concepts, in the introduction of the Origin of German Tragic Drama (1926) Benjamin incorporates and reinterprets some issues contained in Plato's Symposium. It will also be taken into account the text of the Introductory Matters of the Knowledge's Critic, as well as three other unpublished writings of Benjamin in life, namely: The Theory of Criticism,
\end{abstract}

\footnotetext{
${ }^{1}$ Williard Scorpion Pessoa Fragoso é aluno do Doutorado Integrado do Programa de Pós-Graduação em Filosofia das universidades: UFPB, UFRN, UFPE.
} 
Categories of Aesthetics and, finally, On Semblance, all written between years 19 and 20 of the twentieth century.

Key-words: Truth, Beauty, Good and Language.

\section{Considerações Preliminares}

Este artigo propõe algumas reflexões sobre a relação entre o conhecimento, o belo e a linguagem no pensamento do jovem Walter Benjamin. Para tanto lança mão de elementos contidos em certos textos do autor, a saber: as Questões Introdutórias de Crítica do Conhecimento na obra A Origem do Drama Barroco Alemão de 1926; e ainda: três textos de Benjamin não publicados em vida: A Teoria da Crítica, Categorias de Estética e, por fim, Sobre a Semelhança; todos escritos entre os anos 1919 e 1920. Deixamos claro que não se trata de um exercício de exegese textual, mas de um cruzamento de certas perspectivas, certos lances de vista, com a finalidade de ressaltar a importância - e o caráter imprescindível - dos aspectos ontológicos do pensamento de Benjamin.

\section{Questões Epistemológicas}

Logo de início, postularemos que um dos conceitos chaves do pensamento de Benjamin é - ao lado dos atributos materiais do objeto - a Idéia. Neste sentido, não se deve ignorar que "as únicas obras [completas] de um filósofo que ele [Benjamin] tinha em sua biblioteca (...), além de Platão, eram as Obras Completas [Sämtliche Werke], de Baader (...)" (Scholem, 1989, p. 33). Entretanto, sua ontologia não se orienta somente a partir de Platão. Num trecho de uma carta de Benjamin a Florens Christian Rang, datada de 9 de Dezembro de 1923, pode-se ler a seguinte declaração do filósofo berlinense:

Todo o modo de pensar de Leibniz, sua idéia de mônada, a qual adotei para minha definição de idéias (...) - desde que para Leibniz a descontinuidade da totalidade dos números era de decisiva importância para a teoria das mônadas - parece-me que isso foi de uma importância decisiva para a teoria das idéias (BENJAMIN, 2000, vol. I, pág. 389²).

\footnotetext{
2 "Leibniz entire way of thinking, his idea of the monad, which I adopt for my definition of ideas (...) since for Leibniz the discontinuity of whole numbers was decisive importance for the theory of Ideas" (Todas as traduções são de nossa responsabilidade).
} 
Outra relevante - e tardia - referência às mônadas leibnizianas aparece na $17^{\mathrm{a}}$ tese sobre o Conceito de História, na qual Benjamin afirma que "onde o pensamento se detém repentinamente numa constelação saturada de tensões, ele confere à mesma um choque através do qual ele se cristaliza como mônada. O materialismo histórico se acerca de um objeto histórico única e exclusivamente quando este se apresenta a ele como uma mônada"3 (BENJAMIN, 2005, pág. 130).

Postulada uma 'ontologia mínima', mas fundamental, no pensamento de Benjamin, voltaremos nossa atenção para a primeira parte da obra A Origem do Drama Barroco Alemão, Questões Introdutórias de Crítica do Conhecimento, na qual Benjamin começa citando Goethe:

\begin{abstract}
Posto que nem no saber nem na reflexão podemos chegar ao todo, já que falta ao primeiro a dimensão interna, e à segunda a dimensão externa, devemos ver na ciência uma arte, se esperamos dela alguma forma de totalidade no universal, no excessivo, pois assim como a arte se manifesta sempre, como um todo, em cada obra individual, assim a ciência deveria manifestar-se, sempre, em cada objeto estudado (GOETHE, 1984, Materialien zur Geschichte der Farbenlehre - Materiais para a História da Doutrina das Cores - in BENJAMIN, 1984, pág. 49).
\end{abstract}

A referência ao autor do Fausto, não é arbitrária; ela parece orientar a posição assumida por Benjamin, qual seja: a recusa à ciência e à Filosofia (reflexão) o conhecimento e a posse definitivos da totalidade. Aponta, pois, a insuficiência da práxis científica e vê na arte um aceno fragmentado e indefinido à Verdade, de caráter não previsível e não determinável previamente, mas comum, partilhável, a alguma forma de totalidade no universal, na idéia. Teremos, pois, a partir da 'Idéia'/mônada uma convergência e uma emergência entre Arte, Filosofia e Conhecimento; entre o Belo, a Verdade e o Bem.

Ainda nas Questões Introdutórias, o pensador berlinense critica o conceito de sistema filosófico - segundo o autor, típico do século XIX - por considerá-lo impróprio e 'limitado' à expressão do texto filosófico. Segundo Benjamin, o sistema enquanto expressão filosófica antecipa a posse do conhecimento na forma de uma representação do objeto na consciência - mesmo que esta consciência seja transcendental. Além dessa antecipação, o sistema filosófico apresentaria "o perigo de acomodar-se num sincretismo que tenta capturar a verdade numa rede estendida entre vários tipos de

\footnotetext{
${ }^{3}$ No livro 'Walter Benjamin: Aviso de Incêndio' (pág. 130), Michel Lowy nota que [numa] "primeira versão dessa tese, que se encontra nas Passagens (ou trabalho das passagens), em vez do conceito de mônada, aparece o de 'imagem dialética'.
} 
conhecimento, como se a verdade voasse de fora para dentro" (BENJAMIN, 1984, pág. 50), como se o conjunto de dados, colhidos empiricamente por cada ciência e acomodados no "fluxograma do sistema", em seus compartimentos, pudesse identificar e capturar a verdade através do acumulo e do entrecruzamento de suas informações, de sua organização de arquivo.

Deste modo, para Benjamin, o método científico é intrinsecamente tautológico, pois lança uma teia de captura do objeto que pressupõe sua antecipação na consciência; antes da aproximação e do exame, o objeto já é projetado, pré-estabelecido, prédeterminado, enfim, limitado. Decorre disto o prejuízo à questão da verdade no seio do fazer científico. Como se não bastasse, o conhecimento científico, por seu método próprio, lida sempre com o que é particular, nunca com aquilo que confere unidade entre os elementos particulares, fragmentados. "Quanto mais minuciosamente a teoria do conhecimento científico investiga as várias disciplinas, mas claramente transparece a incoerência metodológica dessas disciplinas” (BENJAMIN, 1984, pág. 55).

A forma de expressão filosófica par excellance, privilegiada por Benjamin - que ainda cita a doutrina e o ensaio esotérico - é o tratado, pois ele contém um elemento pedagógico fundamental: a valorização da expressão filosófica enquanto exercício do pensamento. Esta atividade indica o elemento intransponível daquilo que é fundamental para que a filosofia seja:

Fiel à sua forma como apresentação ${ }^{4}$ da verdade e não como guia para o conhecimento. (...) Esse exercício impôs-se em todas as épocas que tiveram consciência do Ser indefinível da verdade, e assumiu o aspecto de uma propendêutica. Ela pode ser designada pelo termo escolástico do tratado, pois este alude, ainda que de forma latente, àqueles objetos da teologia sem os quais a verdade é impensável. (...) a quintessência do seu método é a representação. Método é caminho indireto, é desvio. A representação como desvio é portanto a característica metodológica do tratado. Sua renúncia à intenção, em seu movimento contínuo: nisso consiste a natureza básica do

\footnotetext{
4 Em seu artigo "Do Conceito de Darstellung em Walter Benjamin ou Verdade e Beleza" (GAGNEBIN, 2009, pág. 184), Jeanne-Marie Gagnebin esclarece: O primeiro mal-entendido a ser dirimido é uma questão de tradução. A palavra Darstellung - utilizada por Benjamin para caracterizar a escrita filosófica — não pode, (aliás, nem deve), ser traduzida por "representação", como o faz Rouanet (que comprendeu perfeitamente o alcance do texto, conforme sua "Apresentação" muito esclarecedora demonstra, mas que o traduziu, às vezes, de maneira pouco precisa), nem o verbo darstellen pode ser traduzido por "representar". Mesmo que essa tradução possa ser legítima em outro contexto, ela induz, no texto em questão, a contra-sensos, porque poderia levar à conclusão de que Benjamin se inscreve na linha da filosofia da representação - quando é exatamente desta, da filosofia da representação, no sentido clássico de representação mental de objetos exteriores ao sujeito, que Benjamin toma distância. Proponho, então, que se traduza Darstellung por "apresentação" ou "exposição", e darstellen por "apresentar" ou "expor", ressaltando a proximidade no campo semântico com as palavras Ausstellung (exposição de arte) ou também Darstellung, no contexto teatral (apresentação). Grifo nosso.
} 
tratado. Incansável, o pensamento começa sempre de novo, e volta sempre, minuciosamente, às próprias coisas (BENJAMIN, 1984, pág. 50).

Pode-se perceber, a partir do que foi dito, alguns elementos cruciais, quais sejam: a) a caracterização da filosofia como propendêutica, como ensaio - numa abertura da compreensão como encantamento estético nala partir da idéia -; b) a preservação do absoluto (Idéia/palavra fundadora), sem esgotá-lo; antes como condição para o surgimento e compreensão do mundo; c) a questão da apresentação como desvio, quer dizer, o reconhecimento como de sua falta de objetividade como elemento fundamental para atingir minimamente a realidade do objeto visado e, por último, (d) o caráter obstinado do pensamento e seu movimento circular, infatigável, a formar, ampliar e quebrar círculos, ciclos, e refazendo-os, refazendo-se.

\section{O Mosaico: Conhecimento, Linguagem e Beleza}

Num segundo momento da Introdução ao Drama Barroco, Benjamin utiliza a imagem do mosaico para tratar da apresentação (Darstellung) e, extensivamente, do pensamento. Ele faz uso do mosaico para apresentar o pensamento na perspectiva das rupturas, dos abismos, dos pontos cegos, insuspeitos, que se insinuam no aparente continuum espaço-temporal da razão e, ainda assim, suportam a realidade tal como o homem imediatamente a conhece, num golpe indistinto e inesgotável entre o espanto e a fascinação.

O mosaico, assim como o pensamento, é certa continuidade disforme e, ainda assim, harmônica. Porém, essa construção não é algo estritamente ou tradicionalmente idealista. formado por peças 'disformes', de matizes diversos, que se unem e são capazes de formar uma totalidade compreensível, dotada de beleza e de sentido. "A relação entre o trabalho microscópico e a grandeza do todo plástico e intelectual demonstra que o conteúdo de verdade só pode ser captado pela mais exata das imersões nos pormenores do conteúdo material” (BENJAMIN, 1984, pág. 51). Não se trata, no entanto, de mero materialismo; trata-se daquilo que o objeto comunica como verdade; trata-se, isso sim, de deixar falar a irregularidade das peças, dos elementos, suas particularidades, suas fronteiras, sem prescindir de sua unidade imediata, possibilitada pelo caráter da auto-apresentação do reino das idéias: a idéia é, em primeiro plano, apresentação de si própria antes de sê-lo de qualquer outra coisa. Destarte, "a tarefa do filósofo é restaurar em sua primazia, pela apresentação, o caráter simbólico da palavra, 
no qual a idéia chega à consciência de si, o que é o oposto de qualquer comunicação dirigida para o exterior" (BENJAMIN, 1984, pág. 59).

As idéias são fragmentos da verdade na relação com os atributos e os pormenores do conteúdo material do mundo; elas - as idéias - não são toda a verdade. Entretanto, as idéias são pré-existentes, ontologicamente anteriores; para que o objeto se origine, deve comunicar-se ao pensamento no ato de nomear as coisas. Assim, impõe-se a necessidade de sua pré-existência, sem a qual nenhuma apresentação, nenhum reflexo mínimo, nenhuma contemplação, seria possível; não haveria, pois, a existência de sua instância compreensiva. Por conseguinte, "enquanto o conceito emerge da espontaneidade do entendimento, as idéias se oferecem à contemplação. As idéias são preexistentes. A distinção entre a verdade e a coerência do saber define a idéia como Ser. (...) Como Ser, a verdade e a idéia assumem o supremo significado metafísico que lhes é atribuído por Platão" (BENJAMIN, 1984, pág. 52).

Em seguida, referindo-se ao Banquete de Platão ${ }^{5}$, Benjamin introduz a compreensão segundo qual "a verdade é apresentada como o conteúdo essencial do Belo, o reino das idéias, e a verdade é considerada bela" (BENJAMIN, 1984, pág. 52); tal colocação, segundo o próprio Benjamin, tem fundamental importância para qualquer filosofia da arte, bem como em relação à indicação do conceito de verdade e, portanto, diz respeito também ao conhecimento. Entretanto, seu sentido não deve ser buscado, nem tampouco, assumido em consonância com uma abordagem estritamente lógica e epistemológica, isto empobreceria o mundo das idéias, visto que "a beleza na arte está atrelada ao semblante da totalidade e percepção" (BENJAMIN, 2000, vol. I, pág. 2216) que, por sua vez, encontra-se amparada na dinâmica contemplativa que lega ao pensamento a capacidade de, "incansável, começar sempre de novo, e voltar sempre,

\footnotetext{
5 A tese que Benjamin atribui ao Banquete está, na realidade, mais um tanto mais clara em outros diálogos, por exemplo, no livro VI da República (508e-509a): "Fica sabendo que o que transmite a verdade aos objectos congnoscíveis e dá ao sujeito que conhece esse poder, é a idéia de bem. Entende que é ela a causa do saber e da verdade, na medida em que está é conhecida, mas sendo ambos assim belos, o saber e a verdade, terás razão em pensar que há algo de mais belo ainda do que eles. E, tal como se pode pensar correctamente que neste mundo a luz e a vista são semelhantes ao sol, mas já não é certo tomá-las pelo Sol, da mesma maneira, no outro, é correcto considerar a ciência e a verdade, ambas elas, semelhantes ao bem, mas não está certo tomá-las, a uma ou a outra, pelo bem, mas sim formar um conceito ainda mais elevado do que seja o bem" (PLATÃO, 2001, pág. 308/9). A ascese proposta por Diotima no Banquete (211b-212a), através de uma analogia com 'mito da caverna', no livro VII, parece autorizar uma aproximação de uma interpretação da relação necessária entre o Bem, A Verdade e o Belo. 6 “(...) the beautiful ties itself to perfection".
} 
minuciosamente, às próprias coisas" (BENJAMIN, 1984, pág. 50). Esta posição equivale à renúncia do método determinado pelo conceito de sistema; filiar-se a este método significa correr "sempre o risco de acomodar-se num sincretismo que tenta capturar a verdade numa rede estendida entre vários tipos de conhecimento, como se a verdade voasse de fora para dentro" (BENJAMIN, 1984, pág. 50).

Caminhando entre estas paisagens conceituais, o Belo aparece premido por uma tensão que envolve dois sentidos cruciais: na medida em que ele remete ao reino das idéias, instância sem a qual a verdade não pode exprimir-se (Ausdrücken), (1) o Belo parece assumir uma clara proeminência em relação à verdade; contudo, (2) ao passo em que a Verdade é mostrada como o conteúdo essencial do Belo, sem a qual este seria tido como mero suporte formal, a impressão de uma determinação da verdade pela beleza desfaz-se, deixando aberta a questão sobre o modo como essa relação seria possível. Neste caso, a afirmação de que $a$ Verdade é bela, pode emergir como uma chave mestra à tensão indicada. Sendo a Verdade bela, logo é impossível que se possa prescindir do Belo no instante de sua expressão; este, por seu turno, só surge enquanto relaciona-se com a verdade, e somente em relação a ela; ambos estão irrestritamente ligados e assegurados pelo Bem. O aspecto particular que a expressão artística atinge através da linguagem, seja numa representação pictórica, seja na poesia ou na música, estabelece sua relação com o ser da verdade com fulguração da perfeição, da totalidade, pois "A forma é a lei de acordo com a qual o Belo liga-se à perfeição e à totalidade. Toda forma é misteriosa e enigmática porque ela emerge do caráter imprescrutável do Belo no qual ela está vinculada à aparência. É por esta razão que Goethe observa; 'o belo nunca poderá iluminar a si mesmo"7 (BENJAMIN, 2000, vol. I, pág. 220). E a semelhança encontra-se na relação entre a forma, a aparência e conteúdo. Originariamente - em primeiro plano -, toda linguagem comunica a si mesma como signo funcional passível de sentido, forma que possibilita sua 'comunicabilidade' e pode assumir/aparecer como espectros variados (vários modos de expressão e comunicação), portador de conteúdos possíveis infinitos. Se não fosse assim, ela não conseguiria estabelecer sua função mediadora entre os objetos reais, a idéia e os conceitos.

\footnotetext{
7 "Form is the law according to which the beautiful ties itself to perfection and totality. All form is misterious and enigmatic because it arises from the unfathomability of beauty, where it is bound to semblance. This is why Goethe observes: "Beauty can never obtain clarity about itself".
} 
Ou mais precisamente, toda linguagem comunica ela mesma nela mesma; este é o sentido puro do 'medium' da comunicação. (...) Precisamente porque nada é comunicado através da linguagem, o que é comunicado na linguagem não pode ser externamente limitado ou mensurado e, portanto, toda linguagem contém seu [elemento] incomensurável próprio, [um] infinito constituído de modo único ${ }^{8}$ (BENJAMIN, 2000, vol. I, pág. 64).

O nexo desta relação assenta-se na compreensão de que a Verdade e o Belo são, ambos, expressões do Ser das idéias. Vê-se que a expressão do Belo enquanto Verdade possui um sentido de emergência na contingência do vir-a-ser. Contudo, sem apelo ao que permanece, considerando o eterno devir, o sentido do belo estaria por adquirir um laivo de relativismo que legaria à Verdade a noção de que esta teria uma validade que, por sua vez, dependeria de certas condições de sustentação sem as quais não seria possível. Ora, se a verdade é e não é ao mesmo tempo e, além disso, depende de algo exterior a si mesma, ele perde, imediatamente, seu caráter absoluto, ilimitado, autônomo e "criativo". Sem sua autonomia no absoluto - campo aberto de todas as possibilidades -, a verdade encontra-se a mercê de qualquer disparate; tornar-se-ia em não-ser a qualquer momento, lançando, inesperadamente, tudo ao vácuo.

\begin{abstract}
A essência da Verdade como a auto-representação do reino das idéias garante, ao contrário, que a tese da beleza da Verdade não poderá perder nunca sua validade. Esse elemento representativo da Verdade é o refúgio da beleza. [Posto que] a Verdade não é desvelamento, que aniquila o segredo, mas revelação, que lhe faz justiça, [assim, estamos aptos a compreender porque] compete à verdade garantir o Ser da beleza (BENJAMIN, 1984, pág. $53)$.
\end{abstract}

Para Benjamin, portanto, a Verdade não pode ter um sentido negativo, nem que ele seja transitório; sua natureza essencial não lhe permite, pois “como Ser, a verdade e a idéia assumem o supremo significado metafísico que lhes é atribuído expressamente pelo sistema de Platão" (BENJAMIN, 1984, pág. 52); a Verdade possui sua unidade no Ser, e não em condições extrínsecas a si própria e, assim, também se dá com o Belo em sua relação com a Verdade.

Cumpre-nos, assim, considerar em que sentido pode-se considerar o Belo autônomo. Diante do que já foi dito até agora, parece-nos lícito afirmar que esta autonomia só pode ser afirmada se pensarmos o Belo enquanto Idéia. Bem, fazê-lo envolve, de imediato, uma consequiência direta, a saber: teríamos, portanto, uma cisão

\footnotetext{
8 "Or, more precisely, that all language communicates itself in itself; it is in the purest sense the "medium" of the communication. (...) For precisely because nothing is communicated through language, what is communicated in language cannot be externally limited or measured, and therefore all language contains its own incommensurable, uniquely constituted infinity”. Os grifos são do autor.
} 
entre o belo enquanto idéia, ou seja, tomado universalmente, e entre o belo particular, da obra de arte isolada. O significa isto? Significa, por exemplo, que as obras de arte estariam fadadas à morte, apesar de estarem ligadas em sua origem àquilo que há de perene e constante, quer dizer, a Verdade e ao Belo? Parece-nos que não, "pois ainda que não existissem a tragédia pura ou a comédia pura, que pudessem ser nomeadas à luz dessas idéias, elas poderiam sobreviver" (BENJAMIN, 1984, pág. 66). É o trabalho dos artistas que torna isso possível; pelo processo de criação, com seu trabalho, os artistas individuais preenchem as idéias pré-existentes com conteúdos 'concretos', isto é, conferem materialidade à obra e vida à linguagem estética.

Pode-se, portanto, através da investigação das obras de arte, descobrir sua validade universal, bem como seu caráter singular em relação aos outros fenômenos; a obra de arte, na medida em que revela a Verdade, remete diretamente à origem como uma força de um impacto transcendente que esta possui, e não no sentido de origem enquanto se liga aos conceitos de causa e efeito, pois "o termo origem não designa o vir-a-ser daquilo que se origina, e sim algo que emerge (entspringt) do vir-a-ser e da extinção" (BENJAMIN, 1984, pág. 67). O artista desvela o Belo absoluto em um Belo particular, ele o cristaliza na forma de um objeto-mônada, para poder capturá-lo; entretanto, sua dimensão plena nunca poderá ser percebida pelo artista, cabe ao investigador, ao historiador realizar esta tarefa: libertar o fragmento do Belo e apresentá-lo em toda sua historicidade. Deste modo, ao mesmo tempo que insere o fragmento do Belo no tempo, liberta-o de suas tensões históricas, sociais e ontológicas através de uma confluência entre extremos: aquilo que está no tempo está, concomitantemente, para além do tempo.

Mas, é o artista que realiza a (a)parição do Belo, dinamizando no frêmito da práxis artística, todas as determinações inerentes à obra de arte. E

É nesse sentido que ele [Platão] descreve a Verdade como o conteúdo do Belo. Mas ele [o Belo] não se manifesta no desvendamento e sim num processo que pode ser caracterizado metaforicamente como um incêndio, no qual o invólucro do objeto, ao penetrar na esfera das idéias, consome-se em chamas, uma destruição, pelo fogo, da obra, durante a qual sua forma atinge o ponto mais alto de sua intensidade luminosa (BENJAMIN, 1984, pág. 53/54). 
Relacionamos a compreensão desse processo deve ser aproximada da significação dos termos Sprung e Ursprung e confrontada com a definição de criação dada por Benjamin em seu texto Categorias de Estética e sua ligação com a $14^{\mathrm{a}}$ tese Sobre o Conceito de História. Se o fizermos, seremos apresentados ao salto dialético da revolução, ou melhor, ao Salto do Tigre. Aqui, na tese XIV, a moda é apresentada como exemplo desse salto, como uma modalidade criativa que concentra um apelo temporal em três direções (passado, presente, futuro), embora seu único alvo seja o presente. No sentido revolucionário, o Sprung, o salto, visa libertar o presente de uma tensão opressora que não, ao invés de liberar suas potências criativas, mas aprisiona-o em um movimento retilíneo e uniforme, repetitivo, no lugar de uma dinâmica provocativa. Assim, acaba por causar uma acomodação que impede uma revolução, sendo, portanto, necessário recorrer às forças criativas e destrutivas do passado na direção presente.

Para Walter Benjamin, nas Categorias de Estética, não basta ao Belo emergir de algo assim, como o tigre que salta sobre sua presa; o Belo não pode ser forçado à escala de valores naturais, tampouco pode ser considerado unicamente fruto de relações de um processo determinado por uma física social. “(...) Um objeto criado pode ser definido pelo fato de que sua vida - a qual é tão vigorosa enquanto aquilo que tem saltado de algo - toma parte numa intenção de redenção" (BENJAMIN, 2000, vol. I, pág. 2209). É precisamente neste sentido que Benjamin aproxima o filósofo do artista ao afirmar que "se a tarefa do filósofo é praticar uma descrição do mundo das idéias, de tal modo que o mundo empírico nele penetre e nele se dissolva, então o filósofo assume uma posição mediadora entre a do investigador e do artista" (BENJAMIN, 1984, pág. 54).

No ato da criação encontra-se em confluência o salto em sua relação com o Ser das idéias e com a matéria; portanto, com a origem, ou seja, o Ursprung, no sentido do entspringt, ou seja, daquilo que emerge do fundamento no vir-a-ser. É por esse motivo que "a vida da criação permanece velada na obscuridade, nas trevas do criador, até que ele aparte-se dela" (BENJAMIN, 2000, vol. I, pág. 221 ${ }^{10}$ ). Entretanto, sem o apelo à redenção, esses elementos perderiam sua unidade mística, no absoluto, visto que é o elemento hierofântico que insufla no peito da arte sua aura, a singularidade que habita e se revela em confluência com a universalidade do Ser das Idéias no processo de

\footnotetext{
9 “... a created objeto is defined by the fact that its life - which is higher than that of what has 'sprung' from something - has a share in the intention of redemption"

10 "The life of creation remains veiled in obscurity, in the shadow of the creator, until he detalhes himself form it".
} 
representação; sem o elemento teológico-místico a arte perderia sua ligação com o sublime, com o absoluto e, portanto, com a verdade; sem o artista, a arte perde sua atualidade no mundo. A ausência destes elementos faria com que a expressão do Belo fosse captada apenas pelos olhos cobertos com os véus da cegueira; assim, a única coisa revelada seria um vulto na neblina de uma noite perdida num sonho.

A questão da autonomia do Belo e de seus 'status' carrega em si um projeto de superação que remete, em maior ou menor intensidade, ao embate realismonominalismo. Neste sentido, ao considerar a arte tanto na dimensão da idéia quanto naquela da singularidade concreta enquanto produto de um artista individual, Benjamin intenta superar certos aspectos do nominalismo e o realismo. O primeiro, segundo Benjamin, não aceita a estética como um universal genuíno, recorrendo ao falso universal do conceito para salvá-lo do caráter de mero construto subjetivo; o nominalismo, no afã de impedir que o objeto fosse absorvido pelo universal da idéia, perde, portanto, suas especificidades, repetimos: procedendo assim, ele acaba lançando o objeto no peudo-universal do conceito, ocasionando sua dissolução. A universalidade plena somente é dada na idéia.

Se o realismo admite uma objetividade no mundo das idéias, embora não chegue a correlacioná-la com o mundo dos fenômenos, e revela o objeto da arte mais como uma visão (Anschauung) da empatia do investigador com o objeto investigado, bem, se isso acontece, então, o objeto acaba por desaparecer, dando lugar a um construto psicológico do sujeito. Mas, se Benjamin está descartando tanto uma possibilidade quanto outra, qual seria sua posição?

Bem, ao que tudo indica, Benjamin não pretende assumir o platonismo ao pé da letra e com isso salvar o Belo numa idealidade radical. No instante em que ele recorre ao mundo das idéias é por "fidelidade às coisas"; sem o aparato do mundo das idéias, não haveria possibilidade de um amoroso enlace das coisas. Deste modo, em consonância com a filosofia da linguagem de Benjamin, podemos afirmar que

A existência da linguagem não é co-extensiva apenas a todas as áreas de expressão mental humana nas quais a linguagem é sempre inerente quer de um modo quer de outro, mas absolutamente a tudo. Não há nenhum evento ou coisa, seja de natureza animada ou inanimada que, de algum modo, não 
tome parte na linguagem, posto que ela está na natureza de cada [coisa] para compartilhar seus conteúdos mentais (BENJAMIN, 2000, vol. I, p. 62) ${ }^{11}$.

Todo o real é linguagem que ganha uma expressividade 'reflexiva', contemplativa, através dos enunciados formais elaborados pelo homem nos mais variados modos de sua expressão, seja na arte, seja na ciência; isso não quer dizer, que esteja aprisionada em uma forma de antropomorfismo; quer dizer, antes de mais nada, que se não houvesse uma expressão, uma língua falada silenciosamente pelos objetos do mundo- um elemento perceptivo/comunicativo -, não seria possível falar nada deles.

Através da linguagem, Benjamin acaba por colocar o Conhecimento e o Belo entre extremos: entre a empiria e o idealismo radicais; esta tensão cria condições para uma compreensão da natureza do belo, para sua iluminação filosófica. O conhecimento e o Belo surgem como uma fulguração que é também uma revelação do Ser das idéias e só se liberta no instante em que se materializa, irrompe no mundo; e só pode emergir porque existe enquanto idéia; e ainda: é acessível ao homem enquanto percepção, idéia de percepção, percepção-nome, compreensão da percepção e, por fim, expressão compreensiva pela intermediação na linguagem, subjetiva e intersubjetiva.

Mas, em que lugar as idéias estariam? No 'céu platônico', no mundo empírico ou no conceito? As idéias, para Benjamin, encontram-se no reino intrínseco da linguagem, flanando entre sua dimensão significativa e comunicativa, completando-se na apresentação. Contudo, para libertar o potencial da linguagem, livrando-o do caráter meramente semântico, o filósofo tem que trazer a tona o caráter adamítico da linguagem, ou seja, fundador de uma realidade lingüística das coisas; sem isso, a palavra continuaria empobrecida, mero fragmento semântico, sem poder para nomear as coisas. Para realizar esta tarefa, o filósofo deve reconduzir a palavra ao reino do nome, quer dizer, livrá-la de certo laivo de relativismo e devolvê-la o poder criador, absoluto, que remete, antes de tudo, à Verdade. Assim, através da linguagem, adquirimos a capacidade de reconduzir a palavra à sua morada original e, deste modo, poder guiá-la, enquanto idéia, à dimensão do nome, posto que "as idéias se dão, de forma não-

\footnotetext{
11 "The existence of language, however, is coextensive not only with all the areas of human mental expression in which language is always in one sense or another inherent, but with absolutely everything. There is no event or thing in either animate or inanimate nature that does not in some way partake of language, for it is in the nature of each one to communicate its mental nature in its expression".
} 
intencional, no ato nomeado, e têm de ser renovadas pela contemplação filosófica" (BENJAMIN, 1984, pág. 59).

Neste sentido, sem essa revolução na linguagem, o Belo estaria fadado a perder sua expressividade, seu potencial criativo; estaria, portanto, ligado sempre a uma concepção do Conhecimento que nivela por baixo as diferenças e particularidades do objeto do Conhecimento, ou da obra de arte, para fazer com que eles possam ser subsumidos no universal do Absoluto, o que seria completamente contrário do que se propunha Walter Benjamin. Para o pensador berlinense, o absoluto possui o caráter das possibilidades infinitas e não da totalidade definida, precisa, das coisas e suas relações; nem, tampouco, da posse definitiva do conhecimento. Tanto o Conhecimento quanto a obra de arte dependem da relação que a linguagem tece com a apresentação, a aparência/semelhança e sua momentânea sedimentação no pulso da vida numa forma particular de linguagem. Assim, por fim, Benjamin afirma que:

\begin{abstract}
Nenhuma obra de arte pode aparecer completamente 'viva', sem se tornar mera aparência e deixar de ser uma obra de arte. A vida fulgurante na obra de arte deve aparecer imobilizada como se fosse um encantamento num momento único. A vida fulgurante dentro dela é beleza, a harmonia que flui através do caos e - que só aparecer como fulgor. O que comporta esta aparência, o que assegura o encantamento da vida e interrompe a harmonia é o inexpressivo [das Ausdrucklose]. Aquele fulgor é o que constitui a beleza da obra; a imobilização é o que define a verdade (BENJAMIN, 2000, vol. I, pág. 224).
\end{abstract}

\title{
5. Considerações Finais
}

Ora, tentamos estabelecer a correlação que Benjamin erige entre Conhecimento, Beleza e Filosofia, suas ligações com o conceito de Verdade, Linguagem e Representação, perpassando um tanto rapidamente a questão da autonomia do belo. Para tanto, apelamos para escritos produzidos durante a juventude do autor, tentando apresentar elementos de uma ontologia benjamiana para uma melhor compreensão do caráter necessariamente fragmentário que o autor acolhe em seu pensamento. Evitamos cair numa interpretação ligada a uma ortodoxia marxista que poderia ter comprometido a reflexão filosófica em função de uma atitude político-panfletária. Benjamin vinculouse fortemente ao pensamento de esquerda, mas nunca perdeu o vigor filosófico; 
manteve uma contundência marcadamente metafísica em seus escritos, sempre crítico, contundente, sem deixar-se levar facilmente por "ingenuidades conceituais".

Talvez houvesse outros aspectos a pontuar, tais como: as considerações de Benjamin em relação à filosofia kantiana e em relação à metafísica tradicional, o aspecto teológico que permanece em sua filosofia, entre outros que poderiam ter relevância em nossos apontamentos. Entretanto, decidimos não fazê-lo em função de uma economia da estrutura do texto, tentando preservar os aspectos que julgamos fundamentais referentes à preservação de certa estrutura que a beleza teria frente às vicissitudes do real e aos determinismos sócio-econômicos.

Por fim, devemos asseverar, ainda, que Benjamin tenta uma superação das limitações entre realismo e empirismo, bem como o estabelecimento de pontos necessários de comunicação entre a epistemologia, a estética, a ética e a política. Todo real deve, portanto, ser compreendido a partir da dinâmica que assegura a ligação intrínseca entre o Bem, o Verdadeiro/Conhecimento e o Belo através do conceito, na linguagem, sem separar as idéias e o real. Destarte, segundo Rouanet, para Benjamin,

A tarefa do filósofo é, assim, a de injetar nas idéias o sangue vigoroso da empiria e de salvar os fenômenos, guardando-os no 'recinto das idéias'. Mas a empiria não pode penetrar diretamente no mundo das idéias. Donde a função mediadora do conceito. (...) Pelo conceito, as coisas são divididas em seus elementos constitutivos e, enquanto elementos, podem ingressar na esfera das idéias, salvando-se; inversamente, pelo conceito, as idéias podem ser representadas, tornando-se concretas, graças à empiria desmembrada em seus elementos materiais. Os conceitos conseguem assim 'de um golpe dois resultados: salvar os fenômenos e representar idéias' (ROUANET, Paulo Sérgio. Teoria do Conhecimento in A Origem do Drama Barroco Alemão, 1984, p.13). 
Com este golpe, Benjamin mantém o pensamento na tensão que o impulsiona para sua condição de força e exercício, ou seja, sua posição de filho premido entre a Riqueza (Recurso) e a Pobreza ${ }^{12}$, entre as Idéias e os Objetos do mundo. Assim, a filosofia parece realizar-se no espaço insuspeito que se insinua elegante e perturbadoramente nos pontos cegos da materialidade e na suspensão do fluxo de pensamento que, assombrado diante de si, detém-se a contemplar o enlace do pensamento com a materialidade.

\section{Referências}

BENJAMIN, Walter. A Origem do Drama Barroco Alemão, tradução de Sérgio Paulo Rouanet, São Paulo: Brasiliense, 1984.

.Aviso de Incêndio: Uma Leitura das Teses "Sobre o Conceito de História". Tradução de Wanda Nogueira, [tradução das teses] Jeanne-Marie Gagnebin, Marcos Lutz Müller. São Paulo: Boitempo, 2005.

.Obras Escolhidas vol. II: Magia e Técnica, Arte e Política: Ensaios sobre Literatura e História da Cultura. Tradução de Rubens Rodrigues Torres Filho e José Carlos Martins Barbasa. $7^{\text {a }}$ Ed. São Paulo: Brasiliense, 1994.

Obras Escolhidas vol. I: Magia e Técnica, Arte e Política: Ensaios sobre Literatura e História da Cultura. Tradução de Sérgio Paulo Rouanet. $7^{a}$ Ed. São Paulo: Brasiliense, 1994.

.Selected Writings Vol. I, translated by Rodney Livingstone. Cambridge, Massachusetts, London: The Belknap Press Of Havard University Press, 2000.

.Selected Writings Vol. II, translated by Rodney Livingstone. Cambridge, Massachusetts, London: The Belknap Press Of Havard University Press, 2000.

GAGNEBIN, Jeanne-Marie. Do Conceito de Darstellung em Walter Benjamin ou Verdade e Beleza in KRITERION, Belo Horizonte, nº 112, Dez/2005, p. 183-190

PlATÃO. O Banquete in Coleção Os Pensadores. Traduções e notas de José Cavalcante de Souza, Jorge Paleikat e João Cruz Costal. $2^{a}$ edição. São Paulo: Abril Cultural, 1983.

\footnotetext{
${ }^{12}$ Banquete, 203b-204b.
} 
A República. Tradução e notas de Maria Helena da Rocha Pereira. $9^{a}$ edição. Lisboa: Calouste Gulbenkian, 2001.

SCHOLEM, Gershom. Walter Benjamin: A História de uma Amizade. Tradução de Geraldo Gerson de Souza, Natan Norbert Zins e J. Guinsburg. São Paulo: Perpectiva, 1989. 